\title{
Phylogeny, biogeography and systematic revision of plain long-nosed squirrels (genus Dremomys, Nannosciurinae)
}

Melissa T.R. Hawkins ${ }^{1,2,3,4 *}$, Kristofer M. Helgen ${ }^{2}$, Jesus E. Maldonado ${ }^{1,2}$, Larry L. Rockwood ${ }^{5}$, Mirian T.N. Tsuchiya ${ }^{1,2,4}$, Jennifer A. Leonard ${ }^{3}$

${ }^{1}$ Smithsonian Conservation Biology Institute, Center for Conservation and Evolutionary Genetics, National Zoological Park, Washington DC 20008, USA.

${ }^{2}$ Division of Mammals, National Museum of Natural History, Smithsonian Institution, P.O. Box 37012, Washington DC 20013-7012, USA.

${ }^{3}$ Estación Biológica de Doñana (EBD-CSIC), Conservation and Evolutionary Genetics Group, Avda. Americo Vespucio s/n, Sevilla 41092, Spain.

${ }^{4}$ George Mason University, Department of Environmental Science and Policy, 4400 University Drive, Fairfax, VA 20030, USA.

${ }^{5}$ George Mason University, Department of Biology, 4400 University Drive, Fairfax, VA 20030, USA.

*Corresponding author. Address: Smithsonian Conservation Biology Institute, Center for Conservation and Evolutionary Genetics, National Zoological Park, Washington DC 20008, USA E-mail addresses: 


\begin{abstract}
The plain long-nosed squirrels, genus Dremomys, are high elevation species in East and Southeast Asia. Here we present a complete molecular phylogeny for the genus based on nuclear and mitochondrial DNA sequences. Concatenated mitochondrial and nuclear gene trees were constructed to determine the tree topology, and date the tree. All speciation events within the plain-long nosed squirrels (genus Dremomys) were ancient (dated to the Pliocene or Miocene), and averaged older than many speciation events in the related Sunda squirrels, genus Sundasciurus. Within the plain long-nosed squirrels, the most recent interspecific split occurred 2.9 million years ago, older than some splits within Sunda squirrels, which dated to the Pleistocene. Our results demonstrate that the plain long-nosed squirrels are not monophyletic. The single species with a distinct distribution, the Bornean mountain ground squirrel (Dremomys everetti), which is endemic to the high mountains of Borneo, is nested within the Sunda squirrels with high support. This species diverged from its sister taxa in the Sunda squirrels 6.62 million years ago, and other plain long-nosed squirrels over 11 million years ago. Our analyses of morphological traits in these related genera support the re-classification of the Bornean mountain ground squirrel, Dremomys everetti, to the genus Sundasciurus, which changes its name to Sundasciurus everetti. Past inclusion in the plain long-nosed squirrels (Dremomys) reflects convergent evolution between these high elevation species.
\end{abstract}

Keywords: convergent evolution, Sciuridae, biogeography, Sundaland, morphology, molecular phylogeny 


\section{Introduction}

The biota of Southeast Asia, one of the most threatened and biodiverse in the world, includes multiple biodiversity "hotspots" (de Bruyn et al., 2014; Mittermeier et al., 2005; Myers, 2003) and the world's largest diversity of tree squirrels (Order: Rodentia; Family: Sciuridae). The subfamily Nannosciurinae alone contains 14 genera and over 60 species of tree squirrels (Thorington et al., 2012; Musser et al., 2010; Thorington and Hoffmann, 2005; Corbet and Hill, 1992). The subfamily is distributed from the Indian Subcontinent to China and across mainland Southeast Asia to the Sunda Shelf (Malay Peninsula, Sumatra, Java, Borneo, and associated islands), and has crossed Wallace's and Huxley's Lines into Sulawesi and the Philippines, respectively.

Within this region, Borneo is particularly rich in both diversity and endemism. Of the eight genera of nannosciurine squirrels native to Borneo, only two are also distributed across the Isthmus of Kra into mainland Southeast Asia (Corbet and Hill, 1992; Thorington et al., 2012). One genus distributed north of the Isthmus of Kra, Callosciurus, is a widespread and diverse group in need of revision (Moore and Tate, 1965). The second genus, the plain long-nosed squirrels (Dremomys), is a genus of exclusively high elevation endemics (Thorington et al., 2012; Corbet and Hill, 1992). The plain long-nosed squirrels are drab brown animals with elongate rostra and short bushy tails, with a variable amount of red-orange fur in the pelage (Thorington et al., 2012: Corbet and Hill, 1992). Five of the six species of plain long-nosed squirrels are distributed in mainland Southeast Asia north to China and west to India: Dremomys pernyi, D. lokriah, D. gularis, D. rufigenis, D. pyrrhomerus (Corbet and Hill, 1992; Thorington et al., 2012; Thorington and Hoffmann, 2005). Some of the species have restricted ranges, and 
two, the red-cheeked squirrel (D. Rufigenis), and Perny's long-nosed squirrel (D. pernyi), are widespread. The last species, and the smallest member of the genus, the Bornean mountain ground squirrel (BMGS), Dremomys everetti (Thomas, 1890), is known only from the mountains of Borneo, far disjunct from the geographic ranges of other members of the genus (Fig. 1). A previous phylogenetic study of the species relationships in Dremomys did not include this species (Li et al., 2008). In the past, the BMGS has been classified in other nannosciurine genera, including Funambulus and Rhinosciurus (e.g. Allen and Coolidge, 1940; Banks, 1933). However, classification of the BMGS in Dremomys, based especially on its pelage and relatively long snout, has been accepted for nearly a century (e.g. Corbet and Hill, 1992; Ellerman et al., 1940; Moore and Tate, 1965; Robinson and Kloss, 1918; Thorington et al., 2012; Thorington and Hoffmann, 2005).

In the closely related genus of Sunda squirrels (Sundasciurus), high elevation subspecies of a widespread species (S. tenuis) were found to be genetically divergent from the lowland populations, and so, with morphological support, they were resurrected as independent species (S. tahan, S. altitudinus; den Tex et al., 2010; Thorington et al., 2012). These data hint at the particular taxonomic difficulty presented by high-elevation species, perhaps due to strong abiotic selection leading to convergent phenotypes, similar to the convergence observed in American ground squirrels (Harrison et al., 2003).

Here we use nuclear and mitochondrial DNA sequences to construct a phylogeny for all recognized species of the plain long-nosed squirrels. In addition to the plain long-nosed squirrels, representatives from many closely related genera of nannosciurine squirrels were included in our phylogenetic comparisons, including 16 of the 17 species of the Sunda squirrels, and 10 species of Callosciurus, and a representative of Tamiops, Exilisciurus and Funambulus. We date this 
phylogeny in order to estimate when species and genera diverged, and consider the implications of the phylogeny for understanding the evolution, biogeography, and morphology of these high elevation endemic squirrels. We evaluate each genus for monophyly, and test for association of phylogenetic clades with biogeographic regions. We test the hypothesis that the high elevation environment drives convergent evolution in morphological traits, and place our results in an evolutionary context.

\section{Materials and Methods}

\subsection{Materials}

Tissue samples from twenty-four squirrels were collected for this study and amplified for the three molecular markers. These were combined with published sequences, including 30 individuals for mitochondrial and nuclear genes, and 27 for only cytochrome $b$ (Table 1). Twelve newly acquired tissue samples (nine Dremomys everetti, one Sundasciurus lowii, one S. jentinki, and one Callosciurus prevostii) from field expeditions were collected in Kinabalu Park, Sabah (Borneo), Malaysia. Specimens were collected according to the guidelines of the American Society of Mammalogists (Sikes et al., 2011), as approved by institutional animal care and use committees (Smithsonian Institution, National Museum of Natural History, Proposal Number 2012-04 and Estación Biológica de Doñana Proposal Number CGL2010-21524), with permission from Sabah Parks (TS/PTD/5/4 Jld. 47 (25)), and exported with permissions from the Sabah Biodiversity Council (Ref: TK/PP:8/8Jld.2).

An additional 12 tissue samples were obtained from museum loans from the National Museum of Natural History, Smithsonian Institution, Washington, D.C., USA (USNM); National Zoological Park, Washington, D.C., USA (NZP); Royal Ontario Museum, Toronto, Canada 
(ROM); and the Australian National Wildlife Collection, CSIRO, Canberra, Australia (ANWC) (one Dremomys pernyi, two D. rufigenis, one Exilisciurus exilis, one Funambulus pennantii, one Sundasciurus tenuis, two S. lowii, one Callosciurus adamsi, one C. finlaysonii, one C. orestes, one $C$. phayrei). Published sequences from various muroid outgroups were also included (Table 1).

\subsection{Molecular work}

\subsubsection{DNA extraction, amplification and sequencing}

DNA was extracted from tissue samples with DNeasy Blood and Tissue Kits (Qiagen) following manufacturer instructions. Whole genomic DNA concentration was standardized by spectrophotometry (NanoDrop v 2.0) to approximately $50 \mathrm{ng} / \mu \mathrm{l}$.

Cytochrome $b$ was amplified in two fragments with universal mammalian primers (L14724 [5'-GAT ATG AAA AAC CAT CGT TG -3'], and H15417 [5'-AGT AGG GGT GGA AAG GGA TTT-3'] and L15370 [5'-CAC GAA ACA GGA TCA AAC AAC C-3'] and H15910 [5'-GAT TTT TGG TTT ACA AGA CCG AG-3'], Kocher, 1989) which generated a 1115 base pair (bp) long fragment. PCR reactions consisted of: 1X Gold buffer (Perkin-Elmer, ABI) 0.2 $\mathrm{mM}$ dNTPs, $2 \mathrm{mM}$ of $\mathrm{MgCl}_{2}, 0.5 \mathrm{mM}$ of each primer, and $1 \mathrm{U}$ of Taq Gold (Perkin-Elmer, ABI) in $25 \mu \mathrm{l}$. Cycling conditions were: $95^{\circ} \mathrm{C}$ for $10 \mathrm{~min}$, two cycles of $95^{\circ} \mathrm{C}$ for $15 \mathrm{sec}, 60^{\circ} \mathrm{C}$ for 30 sec, $72^{\circ} \mathrm{C}$ for $1 \mathrm{~min}$, two cycles of $95^{\circ} \mathrm{C} 15 \mathrm{sec}, 58^{\circ} \mathrm{C}$ for $30 \mathrm{sec}, 72^{\circ} \mathrm{C}$ for $1 \mathrm{~min}$, and 19 cycles of $95^{\circ} \mathrm{C}$ for $15 \mathrm{sec}, 56^{\circ} \mathrm{C}$ for $30 \mathrm{sec}, 72^{\circ} \mathrm{C}$ for $1 \mathrm{~min}$, followed by a final extension of $72^{\circ} \mathrm{C}$ for $5 \mathrm{~min}$.

Two nuclear markers were amplified for this study, $c-m y c$ and $R A G-1$. The protooncogene $c-m y c$ is a single copy gene with three exons which has been used to reconstruct 
mammalian, crocodilian, and avian phylogenies (e.g., Braun et al., 1985; Cole, 1986; Yaniv and Jacques, 1997) and has been demonstrated to be phylogenetically informative in squirrels (Steppan et al., 2004). For this study, we sequenced 565 bp of exon 2 of the $c-m y c$ gene using primers S54 [5'- GGAACTATGACCTCGACTACGACTC-3'] and S55 [5'TACAGGATTTGGGCGAGCTG-3'] as in Steppan et al. (2004). The recombination activation gene $(R A G-1)$ is also a single copy gene and consists of one exon uninterrupted by introns (Groth and Barrowclough, 1999). Here we analyzed a 548 bp fragment of $R A G-1$ which was previously found to be phylogenetically informative for mammals, using previously published primers S70 [5'- TCCGAGTGGAAATTTAAGMTGTT-3'] and S105 [5'- CTCCACRGGGTCAGCCAGAAT$\left.3^{\prime}\right]$ as in Steppan et al. (2004).

All PCR products were cleaned with ExoSAP-IT (Affymetrix), then Sanger sequenced using BigDye terminator premix version 3.1 (Applied Biosystems), and separated on an ABI $3130 x \mathrm{l}$ automated capillary sequencer. Geneious v. 7.0.6 was used to remove primer sequences, and to edit and align sequences from all of the fragments used in the analysis.

\subsubsection{Molecular Phylogenetic Analyses}

Cytochrome $b$ and nuclear gene sequence alignments were analyzed separately, as well as concatenated to reconstruct phylogenetic trees with maximum parsimony (MP), maximum likelihood (ML), and Bayesian inference (BI) methods. The cytochrome $b$ dataset included 82 individuals, and the RAG-1 and c-myc contained 45 individuals (Table 1). The MP tree was generated using the parsimony ratchet method (Nixon, 1999) implemented in PAUPRat (Sikes and Lewis, 2001) on the concatenated dataset. The bootstrap support was calculated in PAUP 
v.4.0a136 (Swofford, 2003) using random taxon addition (10 replicates), tree-bisectionreconnection branch swapping, and heuristic searches with 1000 bootstrap replicates.

We used the software PartitionFinder (Lanfear et al., 2012) to determine the best partitioning scheme and model of evolution for each gene. Base composition of all ingroup taxa was tested with a chi-square $\left(x^{2}\right)$ as implemented in PAUP* v.4.0a136. The output from PartitionFinder separated cytochrome $b$ into $1^{\text {st }}, 2^{\text {nd }}$ and $3^{\text {rd }}$ codon positions and neither $c-m y c$ nor $R A G-1$ were partitioned. Under both AIC and BIC, the best-fit models were: $\mathrm{SYM}+\mathrm{I}+\mathrm{G}$ (Zharkikh, 1994) for cytochrome $b 1^{\text {st }}$ codon position (which was modified into a GTR $+\mathrm{I}+\mathrm{G}$ with equal base frequencies for the analyses using BEAST, see below); HKY $+\mathrm{I}+\mathrm{G}$ (Hasegawa et al., 1985 ) for cytochrome $b 2^{\text {nd }}$ codon position; GTR $+\mathrm{G}$ (Tavare, 1986) for cytochrome $b 3^{\text {rd }}$ codon position; $\mathrm{HKY}+\mathrm{G}$ for $c-m y c$; and $\mathrm{GTR}+\mathrm{G}$ for $R A G-1$. The estimated models for each gene were employed to generate a ML tree using the software GARLI (Genetic Algorithm for Rapid Likelihood Inference; Zwickl, 2006) and grid computing (Cummings and Huskamp, 2005) through The Lattice Project (Bazinet and Cummings, 2008). We used ten search replicates and branch support was assessed using 1000 bootstrap replicates.

The same model parameters were applied for the BI analysis in MrBayes version 3.2.2 (Ronquist and Huelsenbeck, 2003) on XSEDE via the Cipres Science Gateway (Miller et al., 2010). The BI analysis was run using 50,000,000 generations along four chains with two replicates at a temperature of 0.05 . The convergence between the two runs was analyzed by comparing the average standard deviation of split frequencies (ASDSF) through Geneious v. 7.0.6. Sample frequency was set to 1,000 with a burn-in of 50,000.

Ancestral range reconstruction was performed to estimate the biogeographic history of these squirrels. The analysis used modern distribution information (mainland Asia, Malay 
Peninsula, Borneo, Sumatra or the Philippines) and the concatenated dataset of cytochrome $b, c$ $m y c$ and RAG-1 (and a PHyML tree as the newick input tree), for ingroup squirrels only using the software Lagrange v.20130526 (Ree and Smith, 2008). Five geographic regions were included in the analysis, $\mathrm{A}=$ mainland $\mathrm{Asia}, \mathrm{M}=$ Malay Peninsula, $\mathrm{B}=$ Borneo, $\mathrm{S}=$ Sumatra and $\mathrm{P}=$ Philippines. The root age was not estimated, the adjacency matrix was left to default, a maximum of 3 biogeographic regions were allowed, and all range combinations were allowed. Dispersal constraints were left to default, and the rates of dispersal and extinction were estimated. Some samples from Genbank data with unknown origin were coded for the entire modern distributional range, otherwise samples were labeled with the known origin of the samples.

Molecular divergence dating was performed in BEAST 1.8 (Drummond et al., 2012) on the XSEDE cluster via the CIPRES Portal (Miller et al., 2010). The BEAST analysis included 71 taxa, with six muroid outgroups, 1 sciuromorph outgroup (Aplodontia rufa), 11 sciurid outgroups, and 53 nannosciurine taxa, with $1074 \mathrm{bp}$ of cytochrome $b, 547 \mathrm{bp}$ of $c-m y c$, and 531 bp of $R A G-1$. Multiple samples of only cytochrome $b$ data were removed when additional individuals representing the same species with complete datasets were present (2 Callosciurus, 7 Sundasciurus, and 2 Dremomys). We used MEGA v5.2.2 to test for a molecular clock using ML values under the Hasegawa-Kishino-Yano (1985) model. The results rejected the null hypothesis, and so a relaxed lognormal clock was used for each partition in BEAST 1.8. We used a Yule process of speciation, and three lognormal calibration points were defined based on the fossil record: 1) 40 MYA (mean: 36.6; 95\% quantiles: 28.8 - 46.5) for the root of Sciuridae, which has been previously used for dating estimates (Eldredge and Stanley, 1984; Mercer \& Roth 2003). All Sciurid taxa were included in this calibration, with the muroid outgroups outside of this taxa 
panel. 2) 24 MYA (mean: 23.9; 95\% quantiles: 20.2 - 28.2) for the split within muroid rodent outgroups, which has been used in previous murine phylogenies (Steppan et al., 2004); and 3) 14 MYA (mean: 14.4; 95\% quantiles: 7.4 - 30.1) for the subfamily Nannosciurinae, which included 60 individuals from three genera (Sundasciurus, Callosciurus and Dremomys) (Qiu, 2002). For all node calibration points, the fossil age was coincident with the median of the lognormal distribution. The evolution rates for each partition were estimated using the lognormal relaxed clock with the operators left to default. Four replicates of 100 million chains were run and evaluated for convergence. An empty alignment was run to evaluate the effect of the priors on the dataset (the ESS values and support from the empty alignment should be different from the full analysis, to determine how much of an effect the priors had on the results). Tracer 1.5 was used to evaluate the convergence of the BEAST runs by assessing the Effective Sample Size (ESS) values, and Tree annotator was used to generate a consensus tree. FigTree v1.4.1 (Rambaut and Drummond, 2012) was used to generate the molecular time tree.

\subsection{Morphological Analyses}

\subsubsection{Material}

One hundred and twenty-five specimens from 12 species, including all recognized species of plain long-nosed squirrels (Corbet and Hill, 1992; Thorington and Hoffmann 2005), were used for morphological analyses (Table S1). In morphometric comparisons, only adults were selected, as determined by closure of the basilar synchondrosis and eruption of all teeth. These squirrels are not sexually dimorphic (Tenzin et al., 2013; Moore and Tate, 1965), and both sexes were included in our analyses. Sixteen cranial measurements (as described in Hayashida et al., 2007) were taken from all six species of plain long-nosed squirrels and six species of Sunda 
squirrels with digital calipers graduated to $0.1 \mathrm{~mm}$. A total of 92 specimens were used for the quantitative traits, and 115 specimens for qualitative traits (Table S1).

\subsubsection{Other craniodental morphology}

For craniodental characters, we examined essentially all specimens of Sunda and plain long-nosed squirrels stored at USNM ( $\sim 750$ specimens). Cranial characters used by other authors to distinguish the two genera (cf. Corbet and Hill, 1992; Moore, 1959, 1958; Moore and Tate, 1965) include the relative length of the rostrum (longer in Dremomys, shorter in Sundasciurus), the relative size and position of the upper premolars, $\mathrm{P}^{3}$ and $\mathrm{P}^{4}\left(\mathrm{P}^{3}\right.$ regarded as small relative to, and situated lateral to, $\mathrm{P}^{4}$, in Dremomys, and larger and more directly anteriorly placed relative to $\mathrm{P}^{4}$ in Sundasciurus: Corbet and Hill, 1992) and the morphology of the auditory bulla (Corbet and Hill, 1992; Moore, 1959, 1958; Moore and Tate, 1965), with the "bullar septae Y-shaped, forming anterior-mesial lobe" (Corbet and Hill, 1992) in Sunda but not in plain long-nosed squirrels. We also documented the presence or absence of the temporal foramen (characteristic of plain long-nosed squirrels, often absent in Sunda squirrels; Moore and Tate, 1965). We evaluated relative rostral length by comparing the length of the nasal bones relative to the condylobasal length of the skull (Tables 2, 3).

\subsubsection{External proportions}

The plain long-nosed squirrels are montane, ground-dwelling squirrels generally characterized by having a relatively short tail compared to other Southeast Asian squirrel genera, including the Sunda squirrels (Corbet and Hill, 1992; Moore and Tate, 1965). We evaluated this aspect in specimens by comparing the length of the tail relative to the head-body length. External 
measurements were taken from specimen tags as measured by the original collectors. Tail length was subtracted from total length to calculate head-body length, if not explicitly given on the specimen tag. A total of 115 specimens were included in these comparisons (Table S1).

\subsubsection{Analysis of morphological data}

RStudio v 0.98.1062 was used to generate a Principal Component Analysis (PCA) for morphometric comparisons of the cranial measurements, and to compare external and cranial proportions for the BMGS to a range of species of plain long-nosed and Sunda squirrels, especially Perny's long-nosed squirrel (D. pernyi) and Low's squirrel (S. lowii) (the respective type species of Dremomys and Sundasciurus). Measurements were transformed to natural logarithms for the PCA. A multivariate analysis of variance (MANOVA) was done on the same cranial measurements as detailed above (also natural logarithm transformed). A Wilks lambda, Pillar's trace and Hotelling-Jawley trace variant of the MANOVA were calculated.

In addition to standard morphometric analysis, we performed a phenotypic trajectory analysis (PTA) (Adams and Collyer, 2009), with the R package 'geomorph' to calculate the phenotypic trajectories for a subset of species included in the morphological analysis. Species included in this analysis were Sundasciurus lowii, S. hippurus, S. tenuis, S. everetti, Dremomys pernyi, and D. rufigenis. Data input to geomorph were the log transformed values from the PCA, with PC1 and PC2 used for the first PTA, and a second comparison performed with PC2 and PC3 to evaluate the effect of $\mathrm{PC} 1$ (which accounted for some $98 \%$ of the observed variation). We also tested the effect of using individual log transformed cranial measurements, with similar results (data not shown). Each replicate was visualized after 1000 iterations. 


\section{Results}

\subsection{Molecular Phylogenetic Analysis}

Cytochrome $b$ (1074 bp), c-myc (548 bp), and $R A G-1$ (533 bp) sequences were generated from all 23 tissue samples (Table 1). RAG-1 contained 25 parsimony informative (PI) sites for alignments containing Dremomys + Sundasciurus and 8 for Dremomys alone (not including the BMGS). C-myc contained 9 PI sites for the Dremomys + Sundasciurus alignment, and 2 for Dremomys alone. All newly generated sequences have been uploaded to Genbank (accession numbers in Table 1). All three genes generated congruent tree topologies, the two nuclear genes generating moderate support alone (data not shown), and strong support when concatenated with mitochondrial data. The most parsimonious tree (of the concatenated dataset) had a tree length of 5982 steps $(\mathrm{CI}=0.218 ; \mathrm{RI}=0.512 ;$ and $\mathrm{RC}=0.112)$. The topology of the single $\mathrm{ML}$ tree was concordant with the MP results (kappa $=3.94, \ln =-30655.86)$. The topology of the BI tree was also concordant, and was more highly resolved than either the MP or ML analyses, with several well supported nodes (Fig. 2).

The relationship between the sequences reported in $\mathrm{Li}$ et al. (2008) was recovered, but the addition of more individuals resulted in the polyphyly of the red-cheeked squirrels (D. rufigenis) with high support (BI 1 and MP and ML bootstrap support > 90). The Vietnam red-cheeked squirrels were more closely related to the red-throated squirrel (D. gularis), and the animals from southern China were more closely related to the red-hipped squirrel (D. pyrrhomerus) (Fig. 2). The sequences included from Li et al. (2008) are only mtDNA data, but were used to include representatives of all species of Dremomys.

All species of plain long-nosed squirrels formed a monophyletic clade with high support (BI posterior probability of 1 and ML $>90$ ) except the BMGS. This species was nested within a 
clade containing members of Sunda squirrels, with high support (BI posterior probability of 0.99 and ML bootstrap of 100). Within the Sunda squirrels, the BMGS clustered within the subgenus Aletesciurus (Moore, 1958), with high support (BI 0.98). The subgenus Sundasciurus was not recovered as monophyletic, as in Den Tex et al. (2010).

\subsection{Molecular dating and ancestral range reconstruction}

The common ancestor of the BMGS and the Sunda squirrels diverged from the lineage leading to the plain long-nosed squirrels approximately 11.61 MYA (95\% HPD 9.1- 14.56) (Fig. 3). The divergence between the BMGS and its closest relatives, which are Sunda squirrels, was estimated at 6.62 MYA (95\% HPD 4.93-8.59). The most recent common ancestor for all plain long-nosed squirrels except the BMGS was estimated at 5.97 MYA (95\% HPD 4.34-7.95), and the common ancestor of all Sunda squirrels including the BMGS was 8.34 MYA (95\% HPD 6.41-10.48). Within plain long-nosed squirrels (except the BMGS), the most recent speciation event was dated to 2.9 MYA (95\% HPD 1.77-4.17, between the Chinese red-cheeked squirrel and the red throated squirrel) and the average age of all of the species was 4.4 MYA (range 5.97-2.9 MYA). Within Sundasciurus (here including the BMGS), the oldest split within the genus was the BMGS (6.62 MYA) with the most recent speciation events in the Philippines during the Pleistocene ( 170,000 years ago). The empty alignment recovered a poorly supported tree, with low ESS values, indicating the priors were not affecting the results, rather the data drove the topology and support observed.

The output from LaGrange recovered ancestral ranges with a maximum of three regions per reconstructed node (see Fig S1). The distribution shown on the ML tree corresponds to the common ancestor of each labelled node. The real probability was at least $85 \%$ for each node. No 
nodes were supported with less than $85 \%$ support. The reconstruction revealed multiple movements from mainland Asia into Borneo, at least four times in the taxa evaluated here (Exilisciurus, Callosciurus, and at least twice from the Sundasciurus, across both recognized subgenera). It appears the clade containing the BMGS moved into Borneo with the most closely related extant taxa distributed in Asia. Our results also suggest that the Malay Peninsula has also been colonized at least five times (by: Dremomys rufigenis, Sundasciurus lowii, Sundasciurus tenuis-tahan, Sundasciurus hippurus, and Callosciurus nigrovitattus). The Philippines appear to have been colonized twice by squirrels.

\subsection{Morphological taxonomy}

Sixteen cranial measurements were taken from 92 individuals representing a variety of species, including all recognized plain long-nosed squirrel species, six species of Sunda squirrels from Borneo and one from the Philippines. The PCA recovered the plain long-nosed squirrels as a distinct cluster, and the Sunda squirrels as two separate clusters. The BMGS fell between the two genera (Fig. S2). The largest bodied species of Sunda squirrels measured, Sundasciurus hippurus and S. philippinensis, comprised a cluster separate from the other squirrels of both genera. In the PCA, 91.78\% of the variance was explained by PC1 alone (a component primarily reflecting overall size), and 2.57\% explained by PC2 (Table S2). When PC2 and PC3 were plotted no additional resolution was visualized (data not shown). The MANOVA revealed significant differences between all species compared (Dremomys pernyi, Sundasciurus lowii and the BMGS; Table S3).

The plain long-nosed squirrels have relatively long rostra and short tails, whereas the Sunda squirrels have shorter rostra and variable tail lengths (Table 2, Figs. 4, S3, S4). The 
BMGS had more variation in tail and rostrum length than mainland plain long-nosed squirrel species (Fig. S3), thus falling morphologically intermediate between the two genera with respect to these characters. Within the Sunda squirrels, rostral length relative to skull length was longer in the montane species (Sundasciurus brookei and S. jentinki) than in lowland species (Table 2). Other characters that have historically been used to discriminate the genera were inconclusive (Table 3). The anteromedial expansion of the auditory bulla of the BMGS was generally intermediate between species of both genera (Fig. 4), and showed considerable variation, generally in the morphological direction of the Sunda squirrels (Moore and Tate, 1965:291). Positional and relative size variation in the upper premolars, regarded as a distinguishing feature between plain long-nosed and Sunda squirrels by Corbet and Hill (1992), was sufficiently variable across the specimens that we did not find it useful to distinguish them. One discrete character that distinguishes the BMGS from the plain long-nosed squirrels is the presence/absence of the temporal foramen (Fig. 4), which, as Moore and Tate (1965: 291) observed, is absent in the BMGS but consistently present (albeit usually very small) in other species of plain long-nosed squirrels. Close examination of specimens at USNM revealed that the temporal foramen is variably present in the majority of Sunda squirrels, but is absent (or present at very low frequency) in several species, especially in those taxa most closely related to the BMGS (Sundasciurus hippurus, S. mindanensis, S. samarensis) and in one other montane endemic $(S$. jentinki). The absence of the temporal foramen in the BMGS is thus a character that is more consistent with its classification as a Sunda squirrel (Sundasciurus) than as a plain longnosed squirrel (Dremomys).

\subsection{Morphological convergence}


In addition to the observation of shared characters such as longer rostral length relative to skull length in the montane species than in lowland species (Table 2), phenotypic trajectory analysis performed using the R package 'geomorph' indicated convergence of BMGS with the high elevation plain long-nosed squirrels (Fig. 5). This analysis shows two trajectories, one which represents the plain long-nosed squirrels, and another for the Sunda squirrels (here including the BMGS), and the points which represent the BMGS have a strong directional pull into the phenotypic space of the plain long-nosed squirrels, providing evidence of phenotypic convergence (see Fig. 5A). When PC2 and PC3 were run on a simplified dataset of only Dremomys pernyi, the BMGS and Sundasciurus lowii the pattern remained the same, with the amount of phenotypic change between the BMGS and Sundasciurus lowii greater than when comparing the BMGS to Dremomys pernyi, implying greater phenotypic difference between the BMGS and the Sundasciurus than the Dremomys (see Fig 5B). Regardless of how we ran the program we recovered similar results, with the BMGS appearing more phenotypically similar to the other species of Dremomys than the Sunda squirrels (including individual morphometric measurements, data not shown).

\section{Discussion}

\subsection{Taxonomic implications}

The polyphyly of the genus of plain long-nosed squirrels caused by the BMGS requires revision of this species (Fig. 2). Both mitochondrial and nuclear DNA supported the placement of the BMGS within the Sunda squirrels. This result is consistent with the biogeography of these generic lineages: the Sunda squirrels are distributed throughout Sundaland (and into the Philippines), and the BMGS is an endemic Sundaic species; while the other plain long-nosed 
squirrels are restricted to mainland Asia. A number of morphological traits, including body size, rostral length, the morphology of the auditory bulla, and the absence of a temporal foramen in the cranium, also support the recognition of the BMGS as a specialized montane representative of Sundasciurus rather than a member of the genus Dremomys (Table 3). Accordingly, we formally re-classify the species here as Sundasciurus everetti. This taxonomic change builds upon previously published observations and impressions that the BMGS was the most divergent species of plain long-nosed squirrel (Corbet and Hill, 1992; Moore and Tate, 1965), and resolves longstanding confusion as to the true generic affinities of the species (e.g. Moore and Tate, 1965; Allen and Coolidge, 1940; Banks, 1933). Presciently, Moore and Tate (1965: 291) previously discussed similarities between the BMGS and the subgenus Aletesciurus of Sundasciurus in the morphology of the auditory bulla, foreshadowing this transfer.

The Sunda squirrels (Sundasciurus) have been traditionally subdivided into two subgenera, Aletesciurus and Sundasciurus (Moore, 1958). Aletesciurus contains one widely distributed species (Sundasciurus hippurus of the Malay Peninsula, Sumatra, and Borneo), and nine species distributed in the Philippines (S. samarensis, S. philippinensis, S. mindanensis, $S$. rabori, S. steerii, S. moellendorffi, S. davensis, S. juvencus, and S. hoogstraali). The subgenus Sundasciurus includes seven species (Sundasciurus altitudinis, S. brookei, S. fraterculus, S. jentinki, S. lowii, S. tahan, and S. tenuis), all distributed in Sundaland (see Fig. 1; Den Tex et al., 2010; Thorington and Hoffmann, 2005; Thorington et al., 2012). Our phylogeny suggests that the Sunda squirrels are made up of 5-6 major phylogenetic lineages of considerable time-depth, which correspond imperfectly to previously recognized subgenera. The subgenus Aletesciurus is monophyletic (including BMGS), but the subgenus Sundasciurus was not recovered as monophyletic (as in Den Tex et al., 2010). For this reason, we suggest suspending the traditional 
classification of Sundasciurus into two subgenera. A more detailed review in the future may show that the various deep lineages or species-groups recovered within Sundasciurus are better recognized as distinct subgenera.

The apparently strong selective forces that drove the convergence between the BMGS and plain long-nosed squirrels may also confound the delineation of other species within the plain long-nosed squirrels. The deep polyphyly in the red-cheeked squirrel may indicate that this species should be split into multiple species. The animals included in this phylogeny are from Vietnam and south China. In their morphological study, Endo et al. (2003) found distinct morphological differentiation between northern and southern red-cheeked squirrels. Both China and Vietnam would be in one of these morphological groups, possibly indicating that this species should be split into at least three species. Studies on morphological variation in the other widespread species, Perny's long-nosed squirrel, also found differentiation between four taxonomic units they referred to as subspecies (Song, 2008). Neither of these morphological studies was able to survey the entire distribution of the target species, and important localities such as Taiwan and Hainan were not included. Further study of the genetic diversity across the range of the recognized species may uncover undescribed species, as was found for the sister genus Tamiops (Chang et al., 2011).

\subsection{Convergent Evolution}

The highest mountains of Borneo are situated in the north of the island, comprising a range spanning over $350 \mathrm{~km}$ in length. Within this mountain chain, Mount Kinabalu is the tallest peak, reaching $4101 \mathrm{~m}$. These uplands constitute a major zone of endemism within Borneo, and the BMGS is one of 22 mammal species endemic to this mountain (Medway, 1977; Payne et al., 
1985). Our phylogeny reveals that the BMGS represents one of four independently evolved lineages of montane endemics (species primarily distributed above $1000 \mathrm{~m}$ ) within the Sunda squirrels. The other three examples are Sundasciurus rabori, endemic to the mountains of Palawan (Heaney, 1979; Heaney et al., 1998); the sister species-pair S. altitudinus and S. tahan, endemic to the mountain chains of Sumatra and the Malay Peninsula, respectively (Den Tex et al., 2010); and S. jentinki, also a Bornean montane endemic (Den Tex et al., 2010; Payne et al., 1985), S. brookei is also endemic to the Bornean mountains, but predominates in hill forests at somewhat lower elevations). Some of the traits that have been suggested to define the plain longnosed squirrels, such as longer rostral length, shorter tail, and dark dense pelage, also characterize high elevation Sunda squirrels. This suggests that these characters are the result of convergent evolution in similar habitats (high elevation tropical forest) as opposed to phylogenetically informative traits. This is supported by the phenotypic trajectory analysis (Fig. 5), which showed the BMGS had more phenotypic similarity to the long-nosed squirrels (Dremomys) than the Sunda squirrels (Sundasciurus). Although the precise mechanism by which selection acts on these traits is not obvious, these traits also characterize other much more distantly related small mammals that share this high elevation habitat, such as the mountain and smooth-tailed treeshrews (Tupaia montana, Dendrogale melanura), and lessure gymnure (Hylomys suillus dorsalis) (Payne et al., 2007), suggesting that they may be adaptive to the montane environment. While this may reflect only coincidence, it remains a largely unstudied area in elevational adaptations, with most research currently focusing on high elevation hypoxia (Storz et al. 2010).

\subsection{Biogeographical implications}


Studies of the biogeography and paleoenvironments of the Sunda Shelf have suggested that during times of low sea level stands, many islands within the Sunda Shelf were connected by forested environments (Cannon et al., 2009; Leonard et al., 2015; Raes et al., 2014; Woodruff, 2010). This geographic history may have been important in producing the remarkable biodiversity observed in Sundaland today (de Bruyn et al., 2014; Leonard et al., 2015), and for the colonization of the Philippines by Sunda squirrels (Fig. 3). Other geological processes, such as volcanic activity and uplifting may also have influenced this biodiversity on a longer time scale (Esselstyn et al., 2009; Heaney, 2000; Jansa et al., 2006). These geological and environmental factors may affect speciation of lowland and highland species differently due to different levels of habitat stability, distribution and connectivity (Cannon et al. 2009; Haq et al., 1987).

During the Miocene the sea level and climate fluctuated greatly (Haq et al., 1987), and likely allowed for the expansion of montane habitat into areas which are presently dominated by lowland forest. This has been modeled for the Pleistocene, but not as far back as the Miocene (Cannon et al., 2009). The expansion of the montane forests during this time period may have allowed for the movement and diversification of montane lineages when additional suitable habitat was available. The lowest sea level has been estimated around 10 MYA, with less dramatic shifts occurring throughout the Miocene, followed by very dramatic fluctuations during the Pleistocene (Haq et al., 1987). The effect of sea level change in Sundaland has likely been significant, with periods of low sea level connecting the various landmasses together, followed by isolation when sea levels rise (see Leonard et al., 2015 for patterns in vertebrate colonization through time). The BMGS diverged from other species of Sundasciurus around 6.6 MYA, which is near a time of low sea level circa 6 MYA (see Mercer and Roth Fig. 3, and Haq et al., 1987), 
and likely implies the diversification events between the BMGS, the S. hippurus clade, and possibly the $S$. tenuis and $S$. lowii clades all diversified following this time of low sea level. While advances have been made in biogeographic modeling (in order to better represent real world examples) complex biogeographical systems such as those that occurred in Sundaland, with repeated waves of colonization and extinction, remain beyond the capacity of these models (Borregaard et al., 2015; Heaney et al., 2013). A model incorporating sea level change through time, may be able to more accurately model scenarios such as this.

High elevation habitats are currently at their minimum extent, and were much more widely distributed throughout most of the Pleistocene, approximately the last two million years (Cannon et al., 2009; Woodruff, 2010). All of these high elevation endemic squirrels appear to be strongly limited in their distribution by environmental factors. The low level of genetic variation identified when multiple individuals from the same region were sampled could suggest that these populations have endured small effective population sizes over long periods of time (Frankham, 1996). This potentially places the populations inhabiting these habitats at increased risk of extinction. Additional habitat perturbation could threaten the survival of these long-persisting species.

The pattern of deep divergences found between the high elevation Sunda squirrels (Den Tex et al., 2010), is mirrored in the high elevation plain long-nosed squirrels. High elevation Sunda squirrels had an average age of sister-species divergence estimated at 4.04 MYA (Sundasciurus rabori, 2.7 MYA, S. tahan-S. altitudinus, 3.72 MYA, S. fraterculus- S. lowii, 2.29 MYA, S. brookei, 6.01 MYA, and S. jentinki 5.5 MYA), similar to the 4.4 MYA estimated here for plain long-nosed squirrels. These dates are much older than the average age calculated for low-elevation species (S. lowii, 1.28 MYA, S. tenuis, 4.73 MYA, S. hoogstraali, 0.23 MYA, $S$. 
juvencus, 0.17 MYA, S. moellendorffi, 0.13 MYA, S. samarensis-S. mindanensis, 0.94 MYA, $S$. philippinensis, 1.2 MYA, S. steeri, 0.61 MYA, and S. hippurus, 1.27 MYA), which averaged to 1.2 MYA. This could imply a different rate of speciation and/ or extinction for species at low versus high elevations. The Philippines represent a very recent colonization of squirrels, although other rodents show a much deeper history on the Philippines, and have also colonized high elevation habitats multiple times (Justiniano et al. 2015).

The ancestral range reconstruction revealed a complex history of movement from Asia to the Sunda shelf, with subsequent colonizations in nearly all possible directions. We recovered at least four colonizations of Borneo, and likely five colonizations of the Malay Peninsula, three to Sumatra, and two into the Philippines. There was also evidence of movement back into Mainland Asia from the Callosciurus species included, which may have a Sundaland origin. This highlights the dynamic history of speciation, analogous to the dynamic history of differentiation between populations within species (Leonard et al., 2015).

Overall, the BMGS represents an endemic lineage adapted to the highlands of Borneo, an area that is home to a large number of montane endemics. The molecular phylogeny has revealed the ancestry of the BMGS is not in the plain long-nosed squirrels, but rather with the Sunda squirrels. The re-classification of the BMGS (Sundasciurus everetti) serves as a reminder that phylogenetic relationships, species boundaries, and geographic distributions within most genera of tropical Asian squirrels remain sparsely studied, obscuring the true evolutionary and biogeographic history, taxonomic diversity, and conservation status of this rich mammalian radiation.

\section{Acknowledgements}


The authors thank Richard Thorington, Jr. and Larry Heaney for guidance, advice, and tissue samples. The field samples collected for this study would not have been possible without the help of Maklarin Lakim, Fred Tuh Yit Yuh, Paul Yambun, and Justin Sator (Sabah Parks, Sabah, Malaysia). The field expedition would not have been successful without the help of the field crew: Miguel Camacho Sanchez, Lyndon R. Hawkins, Flavia Porto Peter, Manuel Lopez Rivera, Francisco Alberto Carro Marino, and the incredible Malaysian staff-Yana Melody, Stephany Disna Ahyu, Foziah Ann, Ipe and Azly and all the porters who made this trip possible. We also extend gratitude to Louise Emmons, Han Kwai and Konstans Wells for the preexpedition advice. Rose Ragai deserves special recognition for tremendous field assistance and serving as a translator. David Aragonés from the GIS and Remote Sensing Laboratory (LASTEBD) of the Doñana Biological Station, CSIC made the map. Megan Krol drew the auditory bulla illustrations. Eliecer Gutiérrez and E. Grace Veatch assisted with generating the PCA, and associated R scripts. Dean Adams provided guidance for using geomorph for the PTA. C. Miguel Pinto and Richard Ree assisted with the Lagrange ancestral range reconstruction. Lyndon Hawkins provided the photograph from Mount Kinabalu, Sabah, Malaysia. Tabitha Viner and the National Zoological Park (Smithsonian Institution), Department of Pathology provided several zoo tissue samples. Tissues were also obtained from Linda Gordon, the National Museum of Natural History, Smithsonian Institution, Washington, D.C., USA; Bill Stanley, Field Museum of Natural History, Chicago; Chris Conroy, Museum of Vertebrate Zoology, Berkeley, USA; Paula Jenkins, Natural History Museum, London, U.K.; Burton Lim, Royal Ontario Museum, Toronto, Canada; and Robert Palmer Australian National Wildlife Collection (CSIRO), Canberra, Australia. Logistical support was provided by the Center for Conservation and Evolutionary Genetics, National Zoological Park, Smithsonian Institution, Washington DC, USA, and 
gratitude is extended to Robert Fleischer, Nancy Rotzel McInerney. Funding was provided by the Spanish Government (CGL2010-21524). Two anonymous reviewers and the associate editor provided comments that greatly improved the quality of this manuscript.

\section{References}

Adams, D.C., Collyer, M.L., 2009. A general framework for the analysis of phenotypic trajectories in evolutionary studies. Evolution 63, 1143-54. doi:10.1111/j.15585646.2009.00649.x

Allen, G.M., Coolidge, H.J., 1940. Mammal and bird collections of the Asiatic primate expedition. Bull Museum Comp Zool 87, 121-166.

Arbogast, B.S., 2007. A Brief History of the New World Flying Squirrels: Phylogeny, Biogeography, and Conservation Genetics. J Mammal 88, 840-849. doi:10.1644/06MAMM-S-322R1.1

Banks, E., 1933. The distribution of mammals and birds in Sarawak and adjacent parts of Borneo. Proc Zool Soc London 103, 272-282.

Bazinet, A.L. and, Cummings, M.P., 2008. The Lattice Project: a Grid research and production environment combining multiple Grid computing models. Distrib Grid Comput Made Transparent Everyone Princ Appl Support Communities 2-13.

Borregaard, M.K., Matthews, T.J., Whittaker, R.J. 2015. The general dymanic model: towards a unified theory of island biogeography? Global Ecology and Biogeography. DOI: $10.1111 /$ geb. 12348 
Cannon, C.H., Morley, R.J., Bush, A.B.G., 2009. The current refugial rainforests of Sundaland are unrepresentative of their biogeographic past and highly vulnerable to disturbance. Proc Natl Acad Sci U S A 106, 11188-93. doi:10.1073/pnas.0809865106

Chang, S.-W., Oshida, T., Endo, H., Nguyen, S.T., Dang, C.N., Nguyen, D.X., Jiang, X., Li, Z.J., Lin, L.-K., 2011. Ancient hybridization and underestimated species diversity in Asian striped squirrels (genus Tamiops ): inference from paternal, maternal and biparental markers. J Zool 285, 128-138. doi:10.1111/j.1469-7998.2011.00822.x

Cheviron, Z.A., Bachman, G.C., Connaty, A.D., McClelland, G.B., Storz, J.F., 2012. Regulatory changes contribute to the adaptive enhancement of thermogenic capacity in high-altitude deer mice. Proc Natl Acad Sci U S A 109, 8635-40. doi:10.1073/pnas.1120523109

Corbet, G.B., Hill, J.E., 1992. The Mammals of the Indomalayan Region: A Systematic Review. Oxford University Press, Oxford.

Cummings, M. P., Huskamp, J.C., 2005. Grid Computing. Educ Rev 40, 116-117.

De Bruyn, M., Stelbrink, B., Morley, R.J., Hall, R., Carvalho, G.R., Cannon, C.H., van den Bergh, G., Meijaard, E., Metcalfe, I., Boitani, L., Maiorano, L., Shoup, R., von Rintelen, T., 2014. Borneo and Indochina are Major Evolutionary Hotspots for Southeast Asian Biodiversity. Syst Biol 63, 879-901. doi:10.1093/sysbio/syu047

Den Tex, R.J., Thorington, R.W.J., Maldonado, J.E., Leonard, J.A., 2010. Speciation dynamics in the SE Asian tropics: Putting a time perspective on the phylogeny and biogeography of Sundaland tree squirrels, Sundasciurus. Mol Phylogenet Evol 55, 711-720.

Drummond, A.J., Suchard, M.A., Xie, D., Rambaut, A., 2012. Bayesian phylogenetics with BEAUti and the BEAST 1.7. Mol Biol Evol 29, 1969-73. doi:10.1093/molbev/mss075 
Eldredge, N., Stanley, S.M. (Eds.), 1984. Living Fossils, in: Casebooks in Earth Sciences.

Springer New York, New York, NY, pp. 23-31. doi:10.1007/978-1-4613-8271-3

Ellerman, J.R., Hayman, R.W., Holt, G.W.C., 1940. The families and genera of living rodents / by J.R. Ellerman ; with a list of named forms (1758-1936) by R.W. Hayman and G.W.C.Holt. British Museum, London : doi:10.5962/bhl.title.8332

Endo, H., Kimura, J., Oshida, T., Stafford, B.J., Rerkamnuanchoke, W., Nishida, T., Sasaki, M., Hayashida, Akiko, Hayashi, Y., 2003. Geographical Variation of Skull Morphology and Its Functional Significances in the Red-Cheeked Squirrel. J Vet Med Sci 65, 1179-1183. doi:10.1292/jvms.65.1179

Esselstyn, J.A., Timm, R.M., Brown, R.M., 2009. Do geological or climatic processes drive speciation in dynamic archipelagos? The tempo and mode of diversification in Southeast Asian shrews. Evolution 63, 2595-610. doi:10.1111/j.1558-5646.2009.00743.x

Fabre, P.H., Hautier, L., Dimitrov, D., Douzery, E.J.P. 2012. A glimpse on the pattern of rodent diversification: a phylogenetic approach. BMC Evolutionary Biology. 12, 88. 1-19.

Fabre, P.H., Pages, M., Musser, GG., Fitriana, Y.S., Fjeldsa, J., Jennings, A., Jonsson, K.A., Kennedy, J., Michaux, J., Semiadi, G., Supriatna, N., Helgen, K.M. 2013. A new genus of rodent from Wallacea (Rodentia: Muridae: Murinae: Rattini), and its implication for biogeography and Indo-Pacific Rattini systematics. Zoological Journal of the Linnean Society. 169, 408-447.

Frankham, R. 1996. Relationship of Genetic Variation to Population Size in Wildlife. Cons Biol 10, 1500-1508.Groth, J.G., Barrowclough, G.F., 1999. Basal divergences in birds and the phylogenetic utility of the nuclear RAG-1 gene. Mol Phylogenet Evol 12, 115-123. 
Haq,B. U., Hardenbol, J., Vail, P. R. (1987) Chronology of fluctuating sea levels since the Triassic. Science 235, 1156.

Harrison, R.G., Bogdanowicz, S.M., Hoffmann, R.S., Yensen, E., Sherman, P.W., 2003. Phylogeny and Evolutionary History of the Ground Squirrels (Rodentia: Marmotinae). J Mammal Evol 10, 249-276.

Hasegawa, M., Kishino, H., Yano, T., 1985. Dating of the human-ape splitting by a molecular clock of mitochondrial DNA. J Mol Evol 22, 160-174. doi:10.1007/BF02101694

Hayashida, A., Endo, H., Sasaki, M., Oshida, T., Kimura, J., Waengsothorn, S., Kitamura, N., Yamada, J., 2007. Geographic Variation in Skull Morphology of Gray-Bellied Squirrel Callosciurus caniceps. J Vet Med Sci 69, 149-157.

Heaney, L., 1979. A new species of tree squirrel (Sundasciurus) from Palawan Island, Philippines (Mammalia: Sciuridae). Proc Biol Soc Washingt 92, 280-286.

Heaney, L.R., 2000. Dynamic disequilibrium: a long-term, large-scale perspective on the equilibrium model of island biogeography. Glob Ecol Biogeogr 9, 59-74. doi:10.1046/j.1365-2699.2000.00163.x

Heaney, L.R., Balete, D.S., Dolar, M.L., Alcala, A.C., Dans, A.T.L., Gonzales, P.C., Ingle, N.R., Lepiten, M. V., Oliver, W.L.R., Ong, P.S., Rickart, E.A., B. R. Tabaranza, J., Utzurrum., R.C.B., 1998. A synopsis of the mammalian fauna of the Philippine Islands. Fieldiana Zool $88,1-61$.

Heaney, L.R., Balete, D.S., Rickart, E.A. 2013. Models of oceanic island biogeography: changing perspectives on biodiversity dynamics in archipelagos. Frontiers of Biogeography. 5 (4) $249-257$. 
Jansa, S.A., Barker, F.K., Heaney, L.R., 2006. The pattern and timing of diversification of Philippine endemic rodents: evidence from mitochondrial and nuclear gene sequences. Syst Biol 55, 73-88. doi:10.1080/10635150500431254

Justiniano, R., Schenk, J. J., Balete, D. S., Rickart, E. A., Esselstyn, J. A., Heaney, L. R., \& Steppan, S. J. (2015). Testing diversification models of endemic Philippine forest mice (Apomys) with nuclear phylogenies across elevational gradients reveals repeated colonization of isolated mountain ranges. Journal of Biogeography, 42(1), 51-64.

Kocher, T.D., 1989. Dynamics of Mitochondrial DNA Evolution in Animals: Amplification and Sequencing with Conserved Primers. Proc Natl Acad Sci 86, 6196-6200. doi:10.1073/pnas.86.16.6196

Lanfear, R., Calcott, B., Ho, S.Y.W., Guindon, S., 2012. Partitionfinder: combined selection of partitioning schemes and substitution models for phylogenetic analyses. Mol Biol Evol 29, 1695-701. doi:10.1093/molbev/mss020

Leonard, J.A., den Tex, R.-J., Hawkins, M.T.R., Muñoz-Fuentes, V., Thorington, R., Maldonado, J.E., 2015. Phylogeography of vertebrates on the Sunda Shelf: a multi-species comparison. J Biogeogr 42, 871-879. doi:10.1111/jbi.12465

Li, S., Yu, F., Yang, S., Wang, Y., Jiang, X., McGuire, P.M., Feng, Q., Yang, J., 2008. Molecular phylogeny of five species of Dremomys (Rodentia: Sciuridae), inferred from cytochrome b gene sequences. Zool Scr 37, 349-354.

Lim, H.C., Rahman, M.A., Lim, S.L.H., Moyle, R.G., Sheldon, F.H., 2011. Revisiting Wallace's haunt: coalescent simulations and comparative niche modeling reveal historical mechanisms that promoted avian population divergence in the Malay Archipelago. Evolution 65, 32134. doi:10.1111/j.1558-5646.2010.01105.x 
Medway, L., 1977. Mammals of Borneo: field keys and an annotated checklist, 2nd edn., Monograph, Malaysian Branch of the Royal Asiatic Society.

Miller MA, Pfeiffer W, S.T., n.d. Creating the CIPRES Science Gateway for inference of large phylogenetic trees. In: Gateway Computing Environments Workshop (GCE)., in: Proceedings of the Gateway Computing Environments Workshop. New Orleans, pp. 1-8. Millien V (2006) Morphological evolution is accelerated among island mammals. PLoS Biol 4(10): e321. DOI: 10.1371/journal.pbio.0040321

Mittermeier, R.A., Gil, P.R., Hoffman, M., Pilgrim, J., Brooks, T., Mittermeier, C.G., Lamoreux, J., Fonseca, G.A.B. da, 2005. Hotspots Revisited: Earth’s Biologically Richest and Most Endangered Terrestrial Ecoregions. Conservation International.

Moore, J.C., 1958. New genera of East Indian squirrels. Am Museum Novit 1914, 1-5.

Moore, J.C., 1959. Relationships among the living squirrels of the Sciurinae. Bull Amer Mus Nat Hist 118, 153-206.

Moore, J.C., Tate, G.H.H., 1965. A Study of the Diurnal Squirrels, Sciurinae, of the Indian and Indochinese Subregions. Fieldiana Zool 48.

Musser, G.G., Durden, L.A., Holden Musser, M.E., Light, J.E., 2010. Systematic review of endemic Sulawesi squirrels (Rodentia, Sciuridae), with descriptions of new species of associated sucking lice (Insecta, Anoplura), and phylogenetic and zoogeographic assessments of sciurid lice. Bull Amer Mus Nat Hist.

Myers, N., 2003. Biodiversity Hotspots Revisited. Bioscience 53, 916-917.

Nixon, K., 1999. The parsimony ratchet, a new method for rapid parsimony analysis. Cladistics $15,407-414$. 
Payne, J., Francis, C.M., Phillipps, K., 1985. A Field Guide to the Mammals of Borneo. The Sabah Society, Kota Kinabalu, Sabah.

Payne, J., Francis, C.M., Phillipps, K., Phillips, K., 2007. A Field Guide to the Mammals of Borneo, 3rd ed. The Sabah Society, Kota Kinabalu, Sabah.

Qiu, Z.-D., 2002. Sciurids from the late Miocene, Lufeng Hominoid Locality, Yunnan. Vertebr Palasiat 40, 179-193.

Raes, N., Cannon, C.H., Hijmans, R.J., Piessens, T., Saw, L.G., van Welzen, P.C., Slik, J.W.F., 2014. Historical distribution of Sundaland's Dipterocarp rainforests at Quaternary glacial maxima. Proc Natl Acad Sci U S A 111, 16790-5. doi:10.1073/pnas.1403053111

Rambaut, A., Drummond, A.J., 2012. Fig Tree: Tree Figure Drawing Tool Version 1.4.

Ree, R.H., Smith, S.A., 2008. Maximum likelihood inference of geographic range evolution by dispersal, local extinction, and cladogenesis. Syst Biol 57, 4-14. doi:10.1080/10635150701883881

Robinson, H.C.C., Kloss, C.B.B., 1918. A nominal list of the Sciuridae of the Oriental Region with a list of specimens in the collection of the Zoological Survey of India. Rec Indian Museum 15, 171-254.

Ronquist, F., Huelsenbeck, J.P., 2003. MrBayes 3: Bayesian phylogenetic inference under mixed models. Bioinformatics 19, 1572-1574. doi:10.1093/bioinformatics/btg180

Sikes, D., Lewis, P., 2001. Software manual for PAUPRat: A tool to implement parsimony ratchet searches using PAUP*. ... http//viceroy eeb uconn edu/paupratweb/pauprat ....

Sikes, R.S., Gannon, W.L., Care, A., of the American Society of Mammalogists, U.C., 2011. Guidelines of the American Society of Mammalogists for the Use of Wild Mammals in Research. J Mammal 91, 235-253. 
Song, L., 2008. Geographic variation of the Perny's Long-nosed squirrels (Dremomys pernyi)(Milne-Edwards, 1867)(Rodentia: Sciuridae) from southwestern China based on cranial morphometric variables. Belgian J Zool 138, 95-100.

Steppan, S.J., Storz, B.J., Hoffmann, R.S., 2004. Nuclear DNA phylogeny of the squirrels (Mammalia, Rodentia) and the evolution of arboreality from c-myc and RAG1. Mol Phylogenet Evol 30, 703-719.

Storz, J.F., 2007. Hemoglobin function and physiological adaptation to hypoxia in high-altitude mammals. J Mammal 88, 24-31. doi:10.1644/06-MAMM-S-199R1.1

Storz, J.F. Scott, G.R., Chevrion, Z.A. 2010 Phenotypic plasticity and genetic adaptation to highaltitude hypoxia in vertebrates. The Journal of Experimental Biology. 213, 4125-4136.

Swofford, D., 2003. PAUP*. Phylogenetic Analysis Using Parsimony (*and Other Methods). Version 4.

Tavare, S., 1986. Some probabilistic and statistical problems on the analysis of DNA sequences. Lec Math Life Sci 17, 57-86.

Tenzin, N., Satasook, C., Bumrungsri, S., Bates, P.J.J., 2013. Does sexual dimorphism exist in squirrels? J Wildl Thail 20.

Thomas, O., 1890. Description of a new Squirrel frm Borneo. Ann Mag Nat Hist ser. 6, 171-172.

Thorington, R.W.J., Koprowski, J.L., Steele, M.A., Whatton, J.F., 2012. Squirrels of the World. Johns Hopkins.

Thorington, Richard W Jr., Hoffmann, Robert, S., 2005. Family Sciuridae, in: Mammal Species of the World. pp. 754-818.

Woodruff, D.S., 2010. Biogeography and conservation in Southeast Asia: how 2.7 million years of repeated environmental fluctuations affect today's patterns and the future of the 
remaining refugial-phase biodiversity. Biodivers Conserv 19, 919-941.

doi:10.1007/s10531-010-9783-3

Yaniv, M., Jacques, S., 1997. Oncogenes as Transcriptional Regulators: Volume 1: Retroviral Oncogenes (Google eBook). Springer, p. 247.

Zharkikh, A., 1994. Estimation of evolutionary distances between nucleotide sequences. J Mol Evol 39, 315-29.

Zwicki, D.J., 2006. Genetic algorithm approaches for the phylogenetic analysis of large biological sequence datasets under the maximum likelihood criterion. The University of Texas at Austin. 


\section{Figure Captions}

Figure 1. Distribution of the plain long-nosed squirrels (genus Dremomys) and the Sunda squirrels (genus Sundasciurus) with the Bornean mountain ground squirrels highlighted separately. Distributions follow Thorington et al. (2012) and Corbet \& Hill (1992). Relevant biogeographic breaks, islands, and elevation (in meters) are labeled.

Figure 2. Bayesian phylogeny of all species of plain long-nosed squirrels, and a variety of nannosciurine species, based on two nuclear and one mitochondrial gene sequences. Support values are abbreviated with BI first, and MP and ML values are abbreviated with a * when bootstrap support was above 80 . Nodes with poor support, or where certain methods generated a polytomy, are indicated with an X. The geographic range of each species is indicated with the following abbreviations following the species, $\mathrm{MA}=$ mainland Asia, $\mathrm{MP}=$ Malay Peninsula, $\mathrm{S}=$ Sumatra, $\mathrm{B}=$ Borneo, $\mathrm{P}=$ Philippines. The BMGS is not labelled, but distributed solely in Borneo.

Figure 3. Dated phylogeny including all species of plain long-nosed squirrels and 16 of the 17 Sunda squirrels. Dates are indicated on the bar at the bottom of the figure in millions of years before present. Node ' $a$ ' is the common ancestor for plain long-nosed and Sunda squirrels, and is estimated to be 11.61 MYA (confidence interval highlighted in blue). Node " $b$ " shows the split within the Sunda squirrels to the Bornean mountain ground squirrels (BMGS) estimated to be 6.62 MYA. Species are colored to match the inlaid map, representative of species distribution, and the BMGS is highlighted in green. A geologic timescale is portrayed at the bottom of the tree. The two subgenera of Sunda squirrels are highlighted with gray boxes. All high elevation 
endemics are marked with a yellow star. The three fossil calibration points are portrayed as the purple triangle (calibration \#2, Murid rodents, $24 \mathrm{MYA}$ ) and the red and green stars (\#1 root of squirrels, 36 MYA, \#3 and "Nannosciurine" 14 MYA calibration point). The photograph above the inlaid map is a BMGS from Kinabalu Park, Sabah, Malaysia.

Figure 4. Comparative photographs of skulls illustrating qualitative cranial characters previously suggested to differentiate the plain long-nosed squirrels from the Sunda squirrels. The type species of Dremomys is Perny's long-nosed squirrel (Dremomys pernyi), represented by USNM 256110, and the type species of Sundasciurus is Low's squirrel (Sundasciurus lowii), represented by USNM 197276. The Bornean mountain ground squirrel (“Dremomys” everetti) is represented by USNM 292628. The white bars highlight the length of the nasal bones in each individual, and the scale bar is for the photographs. In the bottom left is an illustration of a cranium showing the temporal foramen, indicated by the black arrow (modified from Moore and Tate, 1965). Line drawings of the auditory bullae are provided to the right of each skull to clearly illustrate the characters described in the text, and the white arrows highlight the differences observed in the expansion of the third chamber of the auditory bulla between the three species included.

Figure 5. The phenotypic trajectory analysis (PTA) of the plain long-nosed squirrels (Dremomys) and several species of Sunda squirrels (Sundasciurus). A) PTA based on PC1 and PC2 of the PCA including two species of Dremomys (left black dot = average for D. rufigenis, right black dot $=$ average for $D$. pernyi), with small grey dots representing individuals. The open white circles on the bottom line represent the phenotypic average of five species of Sunda squirrels, from left to right, Sundasciurus lowii, S. jentinki, S. tenuis, and S. hippurus. Again the grey 
points represent individuals. The BMGS is the final set of points, which pulls sharply towards the phenotypic space of $D$. pernyi. The black line connects the two species of Dremomys, and the red line connects the Sundasciurus. B) Simplified PTA of only D. pernyi, the BMGS and S. lowii evaluated for PC2 and PC3 of PCA analysis to visualize the effect of PC1. Here D. pernyi is the cluster of grey dots and the average shown as the large black dot on the left side of the figure, with the BMGS shown in the center black dot (average) and surrounding grey points representing all individuals. Sundasciurus lowii is shown averaged in the open white circle, with each individual point shown in grey. The amount of change in phenotypic space is far less between the BMGS and the Dremomys here when compared to $S$. lowii. The combination of both PTA's show that the BMGS has more phenotypic similarity to the Dremomys than to the Sundasciurus, the genus with whom it is most phylogenetically closely related. 
Table 1. Samples included in the molecular analyses and their collection or publication of origin. GenBank accession numbers for the $c-m y c, R A G-1$ and cytochrome $b$ (cyt $b$ ) sequences for each individual are in the last three columns.

Table 2. Average external proportions from representatives of plain long-nosed squirrels and Sunda squirrels measured in this study. The type species of each genus is marked with an asterisk. Abbreviations: $n$, number of individuals from which data were collected; HB, headbody length; Tail, tail length; T/HB proportion of tail to HB; CL, condylobasal length; NL, nasal length; NL/CL proportion of nasal length to skull size. All measurements in $\mathrm{mm}$.

Table 3. Characterization of discrete characters previously used to discriminate between the plain long-nosed squirrels and Sunda squirrels. Characterization of the Bornean mountain ground squirrel, the plain long-nosed squirrels (as represented by Dremomys pernyi, the type species) and the Sunda squirrels (as represented by Sundasciurus lowii, the type species). 
plain long-nosed squirrels

$500-1,000$ $\because::$ Sunda squirrels

ШII Bornean mountain ground squirrel

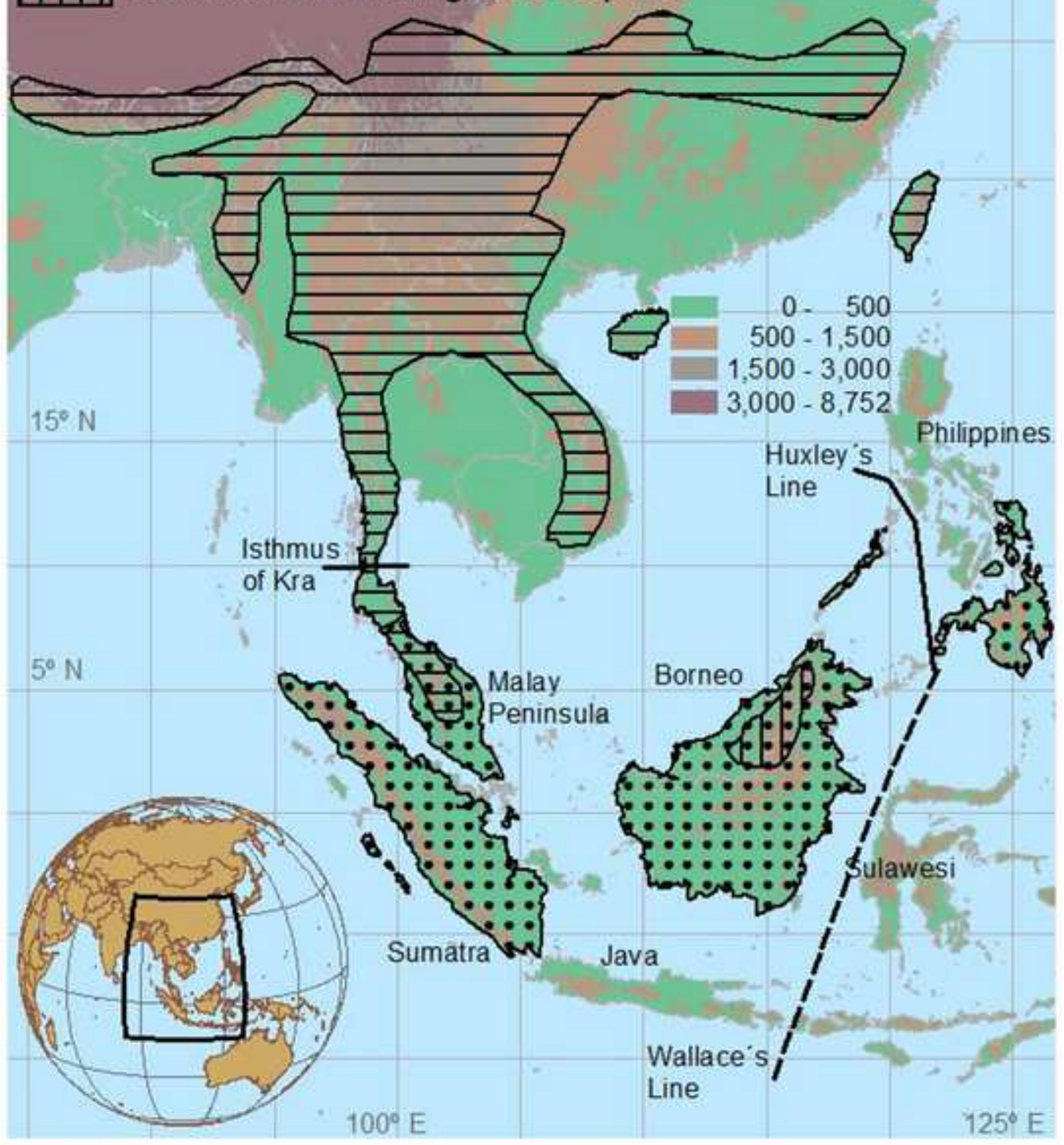




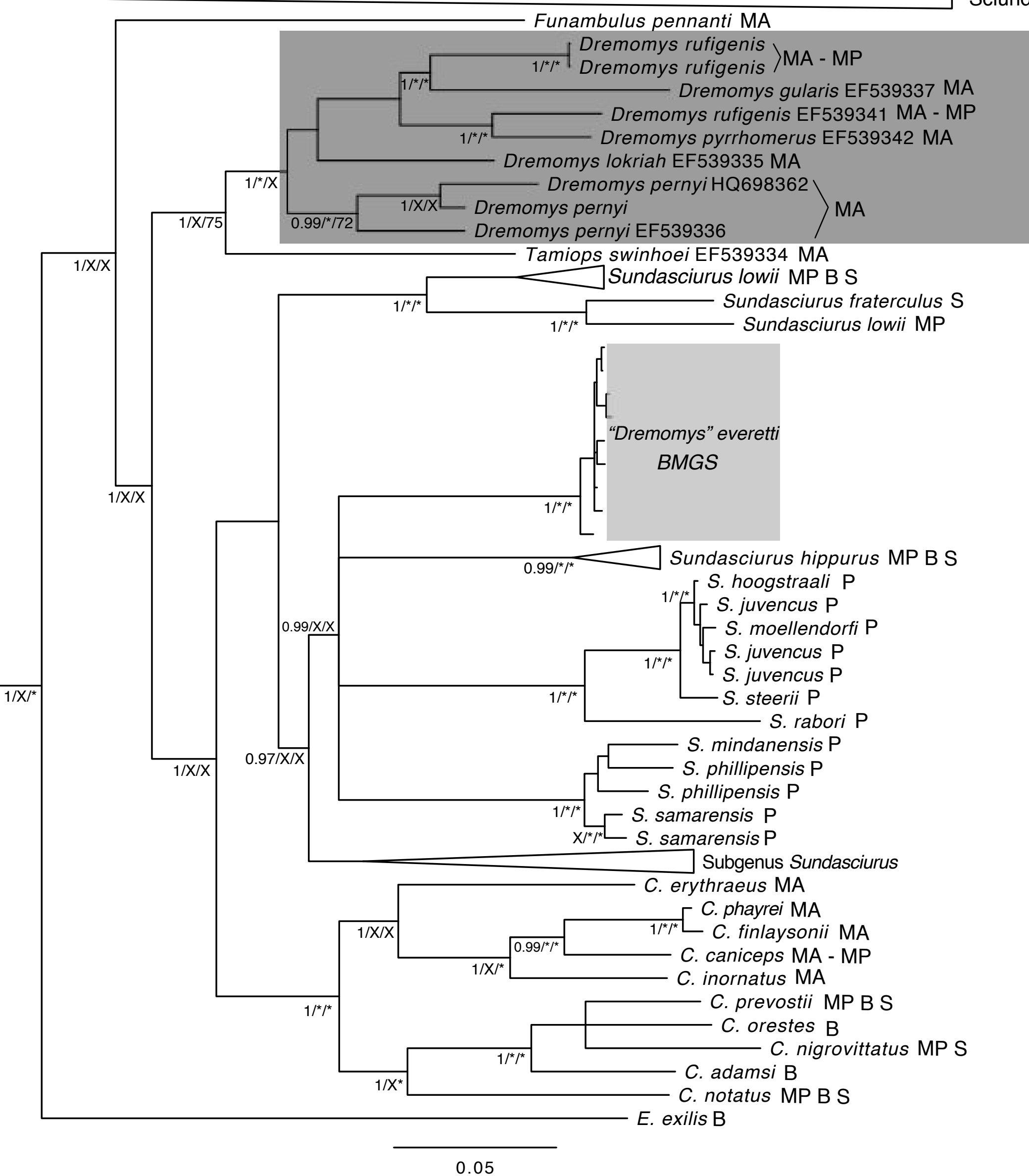




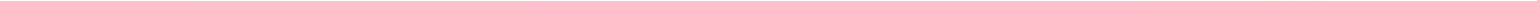




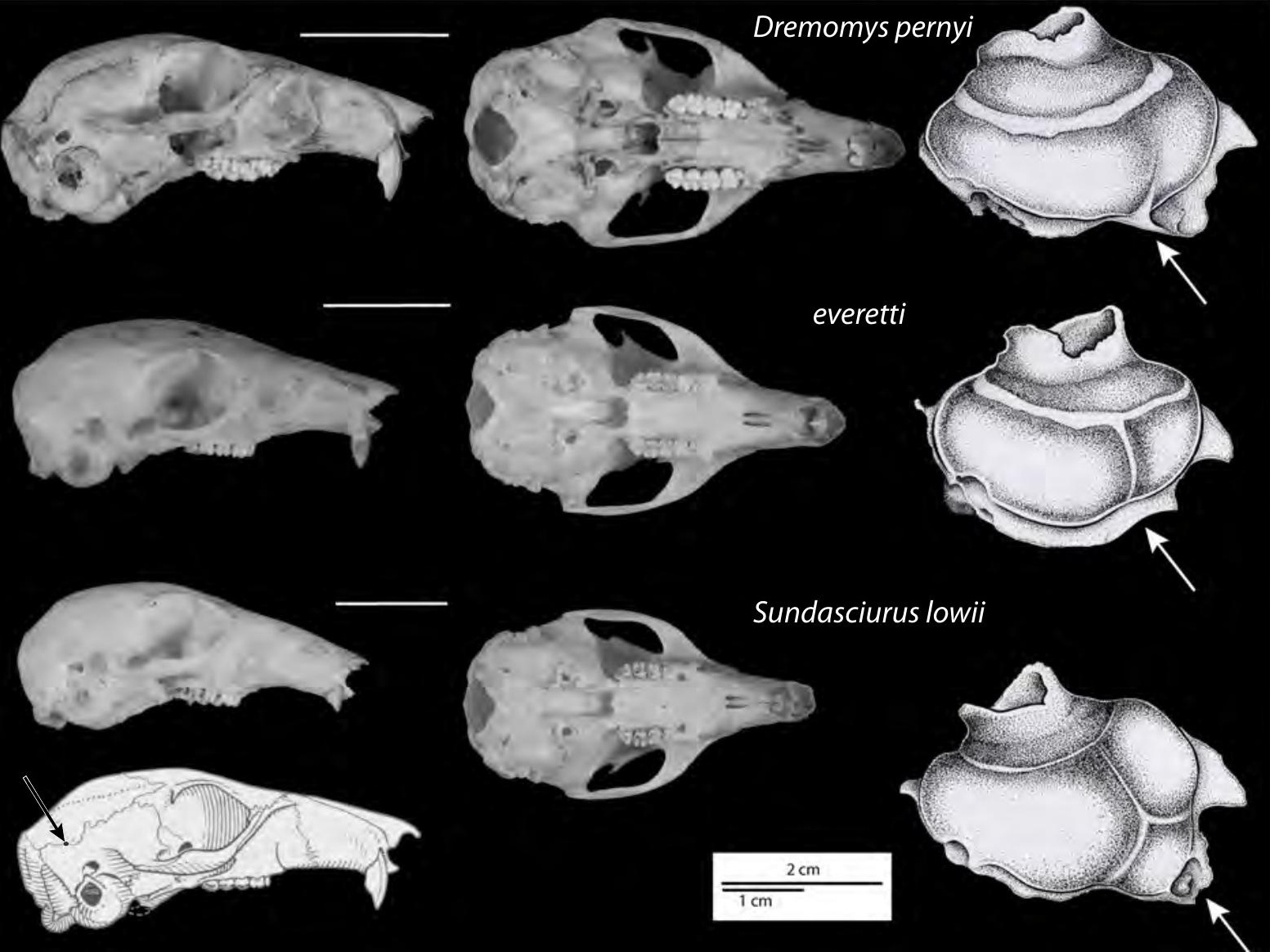




\begin{tabular}{|c|c|c|c|c|c|c|}
\hline Catalog \# or Reference & Species & Country & Specific Location & $R A G-1$ & $c-m y c$ & cyt $b$ \\
\hline Steppan et al. (2004), Piaggio et al. (2013) & Aplodontia rufa & $\overline{\mathrm{N} / \mathrm{A}}$ & $\overline{\mathrm{N} / \mathrm{A}}$ & AY241468 & $\overline{\text { AY239477 }}$ & $=0$ \\
\hline Steppan et al. (2004), Jansa et al. (2006) & Batomys granti & N/A & N/A & AY241461 & AY239472 & DQ191470 \\
\hline NZP 95-322 & Callosciurus adamsi & Malaysia & Sabah, Borneo & KP126010 & KP126058 & KP126035 \\
\hline 64664, Oshida et al. (2001) & Callosciurus caniceps & $\mathrm{N} / \mathrm{A}$ & N/A & N/A & N/A & $\mathrm{AB} 043875$ \\
\hline Steppan et al. (2004), Chang et al. (2010) & Callosciurus erythraeus & N/A & N/A & AY241479 & AY239486 & HQ698360 \\
\hline USNM 584417 & Callosciurus finlaysonii & Myanmar & Mandalay & KP126012 & KP126059 & KP126037 \\
\hline 644236, Oshida et al. (2001) & Callosciurus inornatus & N/A & N/A & N/A & N/A & AB499905 \\
\hline 127501, Oshida et al. (2001) & Callosciurus nigrovittatus & N/A & N/A & N/A & N/A & AB043882 \\
\hline 64678, Oshida et al. (2001) & Callosciurus notatus & N/A & N/A & N/A & N/A & AB499912 \\
\hline ROM 102139 & Callosciurus orestes & Indonesia & East Kalimantan & KP126014 & KP126061 & KP126036 \\
\hline USNM 583884 & Callosciurus phayrei & Myanmar & Mon & KP126013 & KP126062 & KP126038 \\
\hline MTRH118 & Callosciurus prevostii & Malaysia & Sabah, Borneo & KP126032 & KP126057 & KP126056 \\
\hline Steppan et al. (2004), Rowe et al. (2008) & Deomys ferrugineus & N/A & N/A & AY241460 & AY239471 & EU349745 \\
\hline 461707, Li et al. (2008) & Dremomys gularis & N/A & N/A & N/A & N/A & EF539337 \\
\hline 461708, Li et al. (2008) & Dremomys lokriah & N/A & N/A & N/A & N/A & EF539335 \\
\hline Steppan et al. (2004), Chang et al. (2010) & Dremomys pernyi & N/A & N/A & AY241482 & AY239489 & HQ698362 \\
\hline USNM 574326 & Dremomys pernyi & China & Sichuan & KP126028 & KP126063 & KP126039 \\
\hline KIZ 2003012, Li et al. (2008) & Dremomys pernyi & N/A & N/A & N/A & N/A & EF539336 \\
\hline 461709, Li et al. (2008) & Dremomys pyrrhomerus & N/A & N/A & N/A & N/A & EF539342 \\
\hline ROM 111385 & Dremomys rufigenis & Vietnam & Quang Nam & KP126029 & KP126064 & KP126040 \\
\hline ROM 111386 & Dremomys rufigenis & Vietnam & Quang Nam & KP126030 & KP126065 & KP126041 \\
\hline KIZ 2004264, Li et al. (2008) & Dremomys rufigenis & N/A & N/A & N/A & N/A & EF539341 \\
\hline ROM 102254 & Exilisciurus exilis & Indonesia & East Kalimantan & KP126027 & N/A & KP126050 \\
\hline ANU EBU56606 & Funambulus pennanti & Australia & Perth (Introduced) & KP126034 & KP126081 & KP126055 \\
\hline Steppan et al. (2004), Kruckenhauser et al. (1999) & Marmota monax & N/A & N/A & AY241492 & AY239498 & AF100719 \\
\hline $\begin{array}{l}\text { Steppan et al. (2004), Sudman, P.D. and Hafner, } \\
\text { M.S., unpublished }\end{array}$ & Microsciurus flaviventer & N/A & N/A & AY241478 & AY239485 & MFU46169 \\
\hline Steppan et al. (2004), Galewski et al. (2006) & Microtus irene & N/A & N/A & AY241464 & AY239474 & AM392370 \\
\hline $\begin{array}{l}\text { Steppan et al. (2004), Conroy \& Cook (1999) } \\
\text { Steppan et al. (2004), Bernard et al. (1983), }\end{array}$ & Microtus pennsylvanicus & N/A & N/A & AY241463 & AY239473 & AF119279 \\
\hline Hardouin, E.A. and Tautz, D., unpublished & Mus musculus & N/A & N/A & AY241462 & AH005318S1 & JX945964 \\
\hline Steppan et al. (2004), Matthee and Robinson (1997) & Paraxerus cepapi & N/A & N/A & AY241498 & AY239503 & PCU59179 \\
\hline Steppan et al. (2004), Smith and Patton (1999) & Phyllotis xanthopygus & N/A & N/A & AY241466 & AY239475 & AF108693 \\
\hline $\begin{array}{l}\text { Steppan et al. (2004), Sudman, P.D. and Hafner, } \\
\text { M.S., unpublished }\end{array}$ & Sciurillus pusillus & N/A & N/A & AY241471 & AY239480 & SPU46179 \\
\hline Steppan et al. (2004), Liu, X., unpublished. & Sciurotamias davidianus & N/A & N/A & AY241488 & AY239495 & KC005710 \\
\hline Steppan et al. (2004), Barber, B.R., unpublished. & Sciurus carolinensis & N/A & N/A & AY241475 & AY239482 & FJ200685 \\
\hline Steppan et al. (2004), Oshida et al. (2009) & Sciurus stramineus & N/A & N/A & AY241476 & AY239484 & AB292678 \\
\hline Steppan et al. (2004), Harrison et al. (2003) & Spermophilopsis leptodactylus & N/A & N/A & AY241487 & AY239494 & AF157865 \\
\hline BMNH : 1919.11.5.47 Den Tex et al. (2010) & Sundasciurus altitudinus & Indonesia & Sumatra & N/A & N/A & KP120727 \\
\hline USNM 271039, Den Tex et al. (2010) & Sundasciurus altitudinus & Indonesia & Sumatra & N/A & N/A & KP120728 \\
\hline USNM 90570, Den Tex et al. (2010) & Sundasciurus brookei & N/A & N/A & N/A & N/A & KP994921 \\
\hline MTRB7 & Sundasciurus everetti & Malaysia & Sabah, Borneo & KP126015 & KP126067 & KP126045 \\
\hline MTRB8 & Sundasciurus everetti & Malaysia & Sabah, Borneo & KP126016 & KP126068 & KP126046 \\
\hline MTRB11 & Sundasciurus everetti & Malaysia & Sabah, Borneo & KP126017 & KP126069 & KP126047 \\
\hline MTRB12 & Sundasciurus everetti & Malaysia & Sabah, Borneo & KP126018 & KP126070 & KP126049 \\
\hline MTRB15 & Sundasciurus everetti & Malaysia & Sabah, Borneo & KP126019 & KP126071 & KP126048 \\
\hline MTRH151_Kinabalu & Sundasciurus everetti & Malaysia & Sabah, Borneo & KP126020 & KP126076 & KP126051 \\
\hline MTRH163_Kinabalu & Sundasciurus everetti & Malaysia & Sabah, Borneo & KP126022 & KP126079 & KP126052 \\
\hline MTRH168_Kinabalu & Sundasciurus everetti & Malaysia & Sabah, Borneo & KP126023 & KP126078 & N/A \\
\hline MTRH172_Kinabalu & Sundasciurus everetti & Malaysia & Sabah, Borneo & KP126021 & KP126077 & KP126053 \\
\hline USNM 121628 , Den Tex et al. (2010) & Sundasciurus fraterculus & Indonesia & South Pagi Island & N/A & N/A & KP120730 \\
\hline USNM 311463, Den Tex et al. (2010) & Sundasciurus hippurus & Malaysia & Sarawak, Borneo & N/A & N/A & KP120733 \\
\hline USNM 141032, Den Tex et al. (2010) & Sundasciurus hippurus & Indonesia & Sumatra & N/A & N/A & KP120732 \\
\hline USNM 142273, Den Tex et al. (2010) & Sundasciurus hippurus & Indonesia & Sumatra & N/A & N/A & KP120734 \\
\hline USNM 488406, Den Tex et al. (2010) & Sundasciurus hippurus & Malaysia & Selangor & N/A & N/A & KP120731 \\
\hline USNM 477851, Den Tex et al. (2010) & Sundasciurus hoogstraali & Philippines & N/A & N/A & N/A & KP120735 \\
\hline USNM 292576, Den Tex et al. (2010) & Sundasciurus jentinki & Malaysia & Sabah, Borneo & N/A & N/A & KP120736 \\
\hline MTRH 117 & Sundasciurus jentinki & Malaysia & Sabah, Borneo & KP126033 & KP126080 & KP126054 \\
\hline USNM 477866, Den Tex et al. (2010) & Sundasciurus juvencus & Philippines & N/A & N/A & N/A & KP120737 \\
\hline FMNH 196005 Sp_DSB5065, Den Tex et al. (2010) & Sundasciurus juvencus & Philippines & N/A & N/A & N/A & KP120738 \\
\hline FMNH 195288, Den Tex et al. (2010) & Sundasciurus juvencus & Philippines & N/A & N/A & N/A & KP120739 \\
\hline ROM 102098, Den Tex et al. (2010) & Sundasciurus lowii & Indonesia & East Kalimantan, Borneo & N/A & N/A & KP120742 \\
\hline USNM 488447, Den Tex et al. (2010) & Sundasciurus lowii & Malaysia & Selangor & N/A & N/A & KP120740 \\
\hline MTRB17 & Sundasciurus lowii & Malaysia & Sabah, Borneo & KP126024 & KP126074 & KP126042 \\
\hline NZP 93-434 & Sundasciurus lowii & Malaysia & Sabah, Borneo & KP126025 & KP126072 & KP126043 \\
\hline NZP 96-560 & Sundasciurus lowii & Malaysia & Sabah, Borneo & KP126026 & KP126073 & KP126044 \\
\hline USNM 462199, Den Tex et al. (2010) & Sundasciurus mindanensis & Philippines & N/A & N/A & N/A & KP120743 \\
\hline USNM 477947, Den Tex et al. (2010) & Sundasciurus moellendorfi & Philippines & N/A & N/A & N/A & KP120744 \\
\hline FMNH 191420, Den Tex et al. (2010) & Sundasciurus phillipinensis & Philippines & N/A & N/A & N/A & KP120746 \\
\hline FMNH 194781, Den Tex et al. (2010) & Sundasciurus phillipinensis & Philippines & N/A & N/A & N/A & KP120745 \\
\hline FMNH 195285, Den Tex et al. (2010) & Sundasciurus rabori & Philippines & N/A & N/A & N/A & KP120747 \\
\hline EAR1306, Den Tex et al. (2010) & Sundasciurus samarensis & Philippines & N/A & N/A & N/A & KP120748 \\
\hline USNM 458736, Den Tex et al. (2010) & Sundasciurus samarensis & Philippines & N/A & N/A & N/A & KP120749 \\
\hline USNM 477948, Den Tex et al. (2010) & Sundasciurus steeri & Philippines & N/A & N/A & N/A & KP120750 \\
\hline USNM 87085, Den Tex et al. (2010) & Sundasciurus tahan & N/A & N/A & N/A & N/A & KP994922 \\
\hline ROM 102157, Den Tex et al. (2010) & Sundasciurus tenuis & Indonesia & East Kalimantan, Borneo & KP126031 & KP126075 & KP120754 \\
\hline USNM 488459, Den Tex et al. (2010) & Sundasciurus tenuis & Malaysia & Johor & N/A & N/A & KP120751 \\
\hline USNM 488458, Den Tex et al. (2010) & Sundasciurus tenuis & Malaysia & Johor & N/A & N/A & KP120752 \\
\hline $\begin{array}{l}\text { Nunome et al. 2007, Steppan et al. (2004), } \\
\text { Obolenskaya et al. (2009) }\end{array}$ & Tamias sibiricus & N/A & N/A & AB253978 & AY239496 & FJ655250 \\
\hline Steppan et al. (2004), Barber, B.R., unpublished. & Tamiasciurus hudsonicus & N/A & N/A & AY241474 & AY239482 & FJ200685 \\
\hline Steppan et al. (2004), Li et al. (2008) & Tamiops swinhoei & N/A & N/A & AY241481 & AY239488 & EF539334 \\
\hline Steppan et al. (2004), Herron et al. (2005) & Xerus inauris & N/A & N/A & AY241485 & AY239492 & DQ010376 \\
\hline
\end{tabular}




\begin{tabular}{|lccccccccc|}
\hline Species & $\mathbf{n}$ & HB & Tail & T/HB & SD (range) & CL & NL & CL/NL & SD (range) \\
\hline \hline Dremomys everetti & $\mathbf{1 8}$ & $\mathbf{1 6 2 . 3 0}$ & $\mathbf{9 5 . 7}$ & $\mathbf{0 . 5 9}$ & $0.09(0.35-0.73)$ & $\mathbf{3 9 . 2}$ & $\mathbf{1 4 . 1}$ & $\mathbf{0 . 3 6}$ & $0.03(0.31-0.47)$ \\
Dremomys lokriah & 7 & 190.0 & 127.1 & 0.67 & $0.07(0.57-0.77)$ & 42.2 & 15.3 & 0.36 & $0.02(0.34-0.41)$ \\
Dremomys pernyi & 10 & 186.3 & 138.0 & 0.73 & $0.13(0.64-0.88)$ & 44.8 & 16.4 & 0.35 & $0.01(0.36-0.38)$ \\
Dremomys rufigenis & 23 & 186.0 & 145.7 & 0.79 & $0.11(0.52-1)$ & 47.7 & 17.1 & 0.36 & $0.03(0.28-0.42)$ \\
Dremomys pyrrhomeus & 3 & 218.7 & 158.3 & 0.72 & $0.08(0.64-0.78)$ & 50.2 & 16.7 & 0.36 & $0.02(0.33-0.38)$ \\
Dremomys gularis & 1 & 235.0 & 162.0 & 0.69 & N/A (-) & 49.4 & 20.1 & 0.41 & $\mathrm{~N} / \mathrm{A}(-)$ \\
Sundasciurus brookei & 6 & 159.6 & 136.2 & 0.86 & $0.16(0.66-1.03)$ & 37.4 & 12.6 & 0.34 & $0.03(0.31-0.41)$ \\
Sundasciurus hippurus & 16 & 234.9 & 255.1 & 1.09 & $0.11(0.85-1.31)$ & 51.9 & 16.8 & 0.32 & $0.01(0.29-0.34)$ \\
Sundasciurus jentinki & 12 & 127.1 & 116.2 & 0.92 & $0.08(0.79-1.06)$ & 31.1 & 10.3 & 0.33 & $0.02(0.30-0.35)$ \\
Sundasciurus tenuis & 7 & 136.3 & 115.7 & 0.85 & $0.03(0.77-0.88)$ & 31.7 & 10.3 & 0.32 & $0.02(0.30-0.35)$ \\
Sundasciurus lowii & 11 & 127.3 & 86.5 & 0.68 & $0.06(0.53-0.75)$ & 32.9 & 10.4 & 0.32 & $0.01(0.30-0.33)$ \\
\hline
\end{tabular}




\begin{tabular}{|llll|}
\hline Character & Dremomys & "Dremomys" everetti & Sundasciurus \\
\hline \hline Temporal fossa & present (small) & absent & absent \\
Anteromedial expansion & & & \\
of auditory bulla & not pronounced & intermediate & pronounced \\
P3/P4 size/position & inconclusive & inconclusive & inconclusive \\
Rostral length & long & long & short \\
Tail length & generally short & short & short to long \\
\hline
\end{tabular}

1 Moore and Tate 1965, 2 Corbet and Hill 1992 


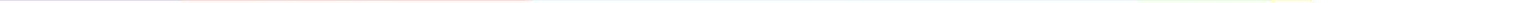

